\title{
Hemlock woolly adelgid niche models from the invasive eastern North American range with projections to native ranges and future climates
}

\author{
Tuula Kantola ${ }^{(1)}$, \\ James L Tracy ${ }^{(2)}$, \\ Päivi Lyytikäinen-Saarenmaa ${ }^{(1)}$, \\ Hannu Saarenmaa ${ }^{(1)}$, \\ Robert N Coulson ${ }^{(2)}$, \\ Antonio Trabucco ${ }^{(3)}$, \\ Markus Holopainen ${ }^{(1)}$
}

\begin{abstract}
The hemlock woolly adelgid (Adelges tsugae Annand - HWA) is invasive in eastern North America where it causes extensive mortality to hemlock communities. The future of these communities under projected climate change is an issue of landscape ecological interest and speculation. We employed the MaxEnt algorithm with the random subset feature selection algorithm (RSFSA) in creating HWA niche models. Final models were ensembles of 12 statistically best models with six predictors each. Out of 119 climatic, topographic, and soil variables, 42 were used in at least one final model. Soil features, followed by climate and topographic features, were most common in selected models. The three most important variables among all models were November potential evapotranspiration, slope, and percent Ochrepts soil. The potential distributions of HWA within eastern North America were projected under historical and four future climate scenarios for 2050 and 2070 under low and high $\mathrm{CO}_{2}$ emissions. The mean of the minimum values for the minimum temperature of the coldest month from the 12 MaxEnt model projections in eastern North America was $-15.8^{\circ} \mathrm{C}$. This value was close to $-15^{\circ} \mathrm{C}$, the extreme minimum temperature found for both HWA occurrence points and previously reported HWA cold temperature limits. These results indicate that HWA may be close to equilibrium distribution in eastern North America under current climate. We also reverse-casted the eastern North American MaxEnt model back onto the HWA native ranges in eastern Asia and western North America. The projections match best with native ranges in Asian islands, such as Japan, and the Cascade Mountains in western North America. Statistically significant HWA range shifts of 221-468 km northwards and 110-164 km eastwards were projected by the 12 models for 2050-2070. The 2070 high $\mathrm{CO}_{2}$ emission scenario models projects HWA suitability throughout most of the northern range of eastern hemlock.
\end{abstract}

Keywords: Ecological Niche Modeling, Climate Change, Hemlock Woolly Adelgid, Invasive Species, MaxEnt, Feature Selection

\section{Introduction}

The hemlock woolly adelgid (HWA Adelges tsugae Annand, Hemiptera: Adelgidae) is a non-native invasive insect in eastern North America causing high mortality to native hemlock species (Spaulding \& Rieske 2010). The HWA was recorded for the first time in Richmond of Virginia, in 1951; however, it was most likely introduced much earlier (McAvoy et al. 2017). The genotype of HWA in the eastern USA originates from low elevations in southern Japan, on southern Japanese hemlock (Tsuga sieboldii Carriére - Havill et al. 2006, 2016). The current aggressive expansion in eastern USA on eastern hemlock (Tsuga canadensis [L.] Carrière) started in the 1980s and was possibly related to climatic factors (Spaulding \& Rieske 2010).

All ten hemlock species (Tsuga spp.) in Asia and North America serve as host species of HWA. However, HWA is a serious pest only on the two native hemlock species of eastern North America, eastern hemlock and Carolina hemlock (Tsuga caroliniana Engelman. - Havill et al. 2006). These hemlocks are observed to have little to no resistance against HWA infestations (McClure \& Cheah 1999). Another reason for the successful HWA establishment in the eastern US is the lack of natural enemies (McClure \& Cheah 1999). Hemlock mortality typically occurs in four to 10 years (Spaulding \& Rieske 2010, McClure et al. 2001), but stand level mortality may occur as soon as in two to three years (Trotter \& Shields 2009). Impacts of hemlock decline by HWA include alterations in ecosystem functions and services, as well as negative effects to other plant species and wildlife (Rohr et al. 2009, Ford et al. 2012). Hemlock decline affect both terrestrial and stream ecosystems.

The eggs and crawlers of HWA are spread by many means, including wind, phoresy on wildlife, and anthropogenic factors (McClure et al. 2001). Estimations of the annual rate of HWA range expansion vary from 12.5 to $20-30 \mathrm{~km}$ (McClure et al. 2001, Morin et al. 2009). Both short and long-distance HWA dispersal has been observed with new colonies found far ahead of the main front of the range expansion (Morin et al. 2009). The rate of range expansion has 
been notably faster pole-wards, compared to the westward, following an anisotropic pattern of spreading (Morin et al. 2009, Soberón \& Peterson 2011). This pattern of spreading may be influenced by phoresy on migratory birds (McClure \& Cheah 1999), as well as abundance and geographical distribution of eastern hemlock (Morin et al. 2009).

The continued spread of HWA coupled with effects of climate change and related range shifts are causing great uncertainty in evaluation of its impact, as well as in risk assessment and management planning (Liang et al. 2014). Predictive models for range expansion support forest health management assisting in preparations for potential further spread (McAvoy et al. 2017). Previous studies have investigated the potential shift of the northern HWA range in relation to winter temperatures and related HWA mortality (Paradis et al. 2008, Fitzpatrick et al. 2012, McAvoy et al. 2017, Ellison et al. 2018). Although cold temperatures are regarded as an important limiting factor for HWA populations (Tobin et al. 2017), other factors should be investigated as well. Topographic features coupled with climate are main drivers of species distribution at a regional scale ( $\mathrm{Pe}$ terson et al. 2011). At higher spatial resolutions, other environmental factors increase in significance, e.g., soil properties, such as soil water holding capacity, which interact with climate (Ehrlén \& Morris 2015). Use of relevant non-climatic variables, such as topography and soil features, with climatic features can produce more robust assessments of the impacts of climate change on species ranges (Iverson et al. 2011).

Ecological niche modeling (ENM, or species distribution modeling) is a popular approach for spatially projecting species distributions under historical (or contemporary) climate and future climate change scenarios (Peterson et al. 2011, Ehrlén \& Morris 2015). This study represents the first use of ENMs to project suitable habitat for HWA within the introduced range of eastern North America under either historical or future climate scenarios. We also reverse-cast introduced range HWA models, projecting them back onto the native range in East Asia and West North America (i.e., reciprocal distribution modeling - Fitzpatrick et al. 2007) in order to: (1) evaluate the sensitivity of the models to HWA occurrences in the native range as an indicator of the degree to which HWA is at equilibrium within the introduced range; and (2) project the most suitable areas in the native range for collecting potential HWA biological control agents adapted to introduced range environments. Accordingly, our primary objectives are to: (1) develop MaxEnt niche models for the introduced population of HWA in eastern North America utilizing 119 environmental variables, including climate, topography and soil features; (2) project the introduced range HWA models back onto the native range of
HWA in Asia and western North America; and (3) project the eastern North American introduced range HWA models to future climates in 2050 and 2070 according to HadGEM2-ES low and high emission scenarios.

\section{Materials and methods}

\section{Environmental predictors}

In this study, we screened a large set of 119 environmental predictors at $1 \mathrm{~km}$ resolution for inclusion in HWA niche models, including 79 climatic variables, 16 topographic variables, 12 soil physical properties, and 12 soil suborders (Tab. S1 in Supplementary material). Soil physical characteristics and topographic variables are important as modifiers of climate, including soil water holding capacity and topographic sun exposure in future climate niche modeling (Ehrlén \& Morris 2015). Since the hemlock woolly adelgid is dependent upon hemlock as a food source, the interaction of soil and topographic features with climate was regarded as particularly important for identifying environmental conditions suitable for hemlock. Soil features included the distribution of soil suborders that have been previously reported as associated with hemlocks (Burns \& Honkala 1990) and which overlap with global Tsuga spp. distributions (Farjon 1990 - Tab. S1 in Supplementary material).

\section{Study extent and species occurrence records}

Limited samples of occurrence observations in the native range of a species may fail to approximate the extent of suitable environments, and ENMs developed from such data may lack transferability to novel regions or differing spatial scales (Menke et al. 2009, Peterson et al. 2011). In addition, Menke et al. (2009) suggested that models built on occurrences from one area and projected to a highly disparate area with different environmental gradients may be prone to errors. Errors in model transferability may be more pronounced when ENMs are used in predicting range shifts of invasive species that have altered their niche requirements in their new environments (Urban et al. 2007). Due to the limited sparse and clustered pattern of the HWA observations in Asia, especially in the continental Asia, we only utilized HWA observations from eastern North America for developing and calibrating HWA niche models. Global HWA occurrence records were obtained from a variety of sources (see Appendix 1 in Supplementary material). Some occurrence records were downloaded from the Global Biodiversity Information Facility (GBIF) and iNaturalist or georeferenced from available HWA maps. However, most of the data were received from scientists and forest managers in the US and Canada. We gathered 4,219 HWA observation with high spatial accuracy and unique location form the eastern North
America (Fig. 1). We also updated the county level infestation map according to the occurrence data set (Fig. 1).

\section{MaxEnt model calibration}

We developed the MaxEnt models from the introduced eastern North American HWA occurrence observations employing the "dismo" package (Hijmans et al. 2011) in R ( $R$ Core Team 2017). Since the HWA population may not yet be in equilibrium and expanded to its full potential range in eastern North America, we developed a calibration background evaluation extent represented by a narrow $20 \mathrm{~km}$ buffer from a convex hull polygon of current presence points (Fig. 1). We generated about 10,000 pseudoabsence points within the background evaluation extent, buffered at $20 \mathrm{~km}$ from presence points, for model evaluation. The "PresenceAbsence" package by Freeman \& Moisen (2008) was used with presence and pseudoabsence data to calculate pseudoabsence-based ( $p s a)$ versions of the True Skill Statistic (TSS psa) and Area under the Curve statistic $\left(A \cup C_{\mathrm{psa}}\right)$. To reduce MaxEnt model complexity and overfitting for improved model generalization, the MaxEnt beta regularization was adjusted to two and only quadratic and hinge features were used (Warren \& Seifert 2011, Tracy et al. 2018). MaxEnt models were calibrated to binary presence/absence format using a threshold at maximum TSS $_{\text {psa }}$ (Liu et al. 2013).

\section{Feature selection}

The 119 environmental predictors were screened to produce smaller selected feature subsets for inclusion in final MaxEnt models using the random subset feature selection algorithm (RSFSA) of Tracy et al. (2018). The RSFSA first generated hundreds of random subsets of environmental predictors (features) of specified sizes that were restricted by a correlation filter of $r=$ |0.7| maximum inter-variable correlation (Dormann et al. 2013). The random feature subsets were then used to develop MaxEnt models that were ranked in performance by subset wrappers of $A U C_{p s a}$ or the corrected Akaike information Criterion (AICC). Results were then used to select an optimal smaller subset size beyond which improvements in $A U C_{p s a}, A I C c$, and overfitting $\left(A \cup C_{\text {test }}-\right.$ AUC $_{\text {train }}$; Warren \& Seifert 2011) were minimal. The statistical performance of RSFSA-selected versus random MaxEnt models was evaluated after generating and ranking thousands of models for the selected subset size using held out model training and testing data (for details, see Tracy et al. 2018). The binary calibrated twelve top RSFSA-selected MaxEnt models were combined by frequency consensus to form a feature subset ensemble (FSE).

\section{MaxEnt model projections and range} shifts

The 12 RSFSA-selected MaxEnt models calibrated for the introduced eastern North 


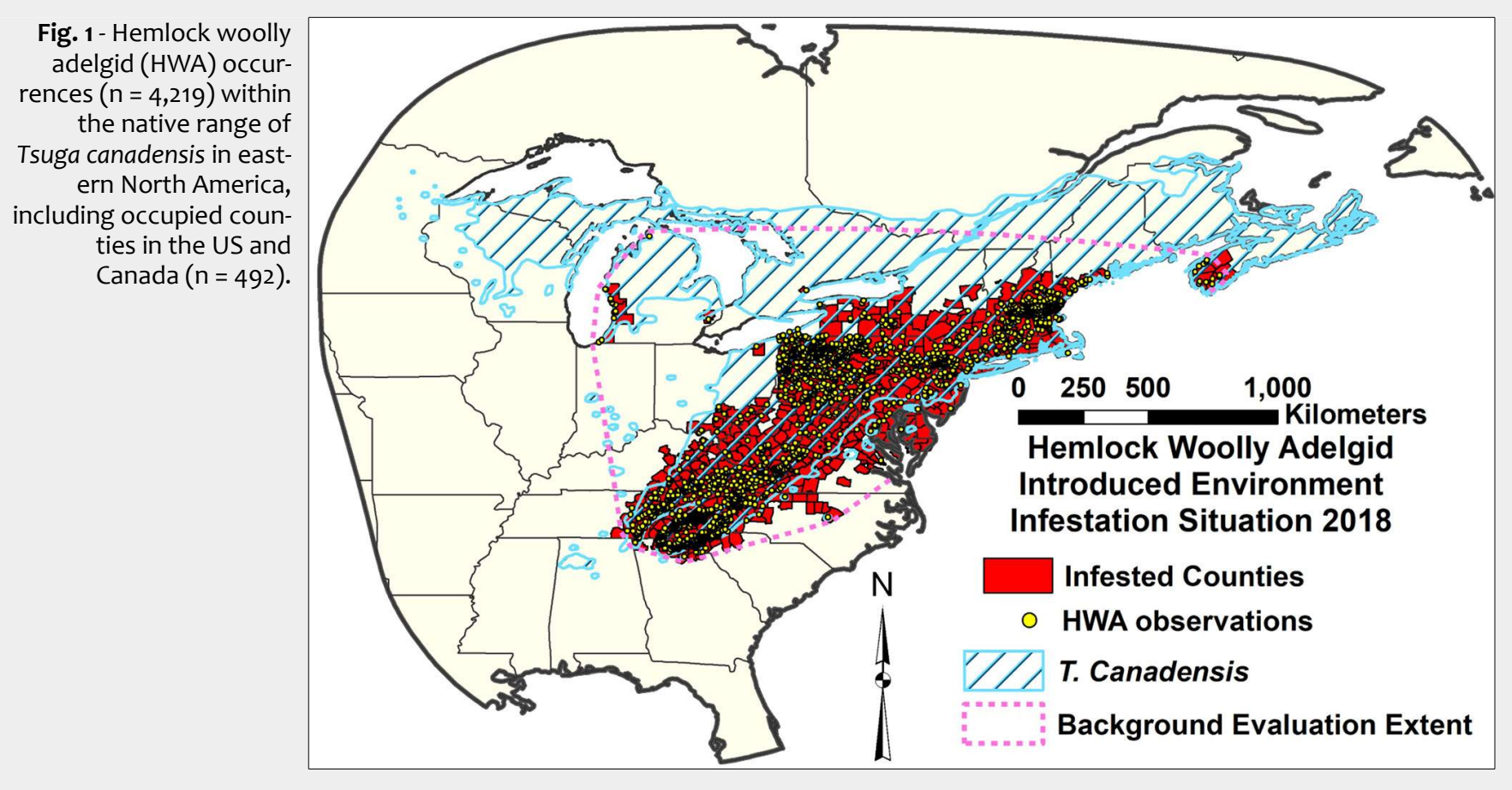

American range were first projected over a wider extent in eastern North America delimited by an $800 \mathrm{~km}$ buffer around the HWA occurrence observations (Fig. 1). The introduced range models were then reverse-cast projected to the species native ranges to East Asia and western North America over areas buffered from HWA occurrence observations by $2,000 \mathrm{~km}$ and $800 \mathrm{~km}$, respectively. Presence data over much of the native HWA continental range in Asia was not available, especially west of China, making generation of pseudoabsence data outside $20 \mathrm{~km}$ buffers from presence data for calculating specificity and AUC more prone to error. Consequently, in order to assess the performance of HWA models generated for eastern North America on the native range, we used the sensitivity statistic, which does not require pseudoabsence data (Jiménez-Valverde et al. 2011). We also calculated sensitivity reverse transferability index (sensitivity native range - sensitivity introduced range; Heikkinen et al. 2012).

The 12 introduced range HWA models were also projected onto four future climate scenarios for eastern North America that were based on the Hadley Centre's HadGEM2-ES general circulation model with low and high representative concentration pathways for $\mathrm{CO}_{2}$ emissions (RCP 2.6 and RCP 8.5) for 2050 (2050he26 and 2050he85) and 2070 (2070he26 and 2070he85). We developed change detection maps between the contemporary climate and the four future climate scenarios. The 12-model MaxEnt feature subset ensemble projection under historical climate was subtracted from ensembles of each of the four future projections. The resulting maps show the change in the number of models projecting HWA habitat suitability. We also quantified the north/south and east/west shifts in centroids for each of the 12 MaxEnt historical climate models paired with the future climate models. Mean elevations within binary historical and future climate models were also compared.

\section{Results}

\section{Feature selection}

The random subset feature selection algorithm revealed that little gain in AUC, AICC, or overfitting was achieved for MaxEnt models using feature subsets larger than six of 119 variables (Fig. S1 in Supplementary material). The six-variable MaxEnt models selected by AUC performed significantly better in terms of AUC, AICC, and overfitting compared to random six-variable models (Fig. S1). A total of 42 variables out of 119 were used in the top 12 RSFSAselected six-variable MaxEnt models (Tabs. S1-S4 in Supplementary material). Nineteen variables were used in more than one of the top 12 models. From one to three of the six variables per model were climate variables. The percentages of variable types selected for the models were $41.7 \%$ edaphic indices, $37.3 \%$ climate indices, and $20.8 \%$ topographic indices (Tab. S1). The edaphic indices include $25 \%$ soil properties (e.g., \% silt from 0-5 cm), and $16.7 \%$ soil taxonomy indices (e.g., \% Ochrepts suborder per $1 \mathrm{~km}$ cell). From the 79 climatic layers, the evapotranspiration layers (actual and potential evapotranspiration: AET-PET) were the most often (15.2\%) utilized (e.g., mean monthly November PET), followed by monthly temperature/precipitation indices $(13.8 \%$ - e.g., mean maximum temperature in February), and BioClim indices $(8.3 \%$ - e.g., mean temperature of the wettest quarter: bio_8). The six highest ranked variables by mean MaxEnt model permutation importance and frequency of appearance in the selected 12 models were: (1) November mean PET; (2) slope; (3) \% Ochrepts soil; (4) \% silt in 0-5 cm; (5)\% Udepts soil; and (6) February mean maximum temperature (Tab. S2 in Supplementary material). Eight of the top 12 ranked climate variables were from the winter season. MaxEnt variable response curves indicated that intermediate levels of November PET and February maximum temperatures were optimal for HWA, as were greater slope and greater percent Ochrepts and Udepts soils. The suitability of \% silt at $0-5 \mathrm{~cm}$ sharply peaked at around $45 \%$ (Fig. S2).

\section{Introduced range distribution maps}

The RSFSA-selected MaxEnt models under historical climate projected suitable habitat for HWA over much of the native eastern hemlock range in the US to the southernmost part of Canada (Fig. 2). The $100 \%$ model consensus area ranges approximately from 44 degrees in the northeast to 34 degrees in the South. Within the southern range, high elevation Southern Appalachians are more suitable for the species than the surrounding low elevation areas. A lower number of models projected suitability of the westernmost range for the eastern hemlock and mid- to north Nova Scotia. The northern part the hemlock range $\left(>45^{\circ} \mathrm{N}\right)$ was generally projected as unsuitable for HWA under contemporary climate. The 12 MaxEnt HWA models covered areas with minimum values for the minimum temperature of the coldest month (bio6) averaging ( \pm standard deviation) $-15.80 \pm 0.47{ }^{\circ} \mathrm{C}$, minimum values for the mean temperature of the coldest quarter (bio11) averaging -7.97 \pm $0.46{ }^{\circ} \mathrm{C}$, and maximum values for the maxi- 


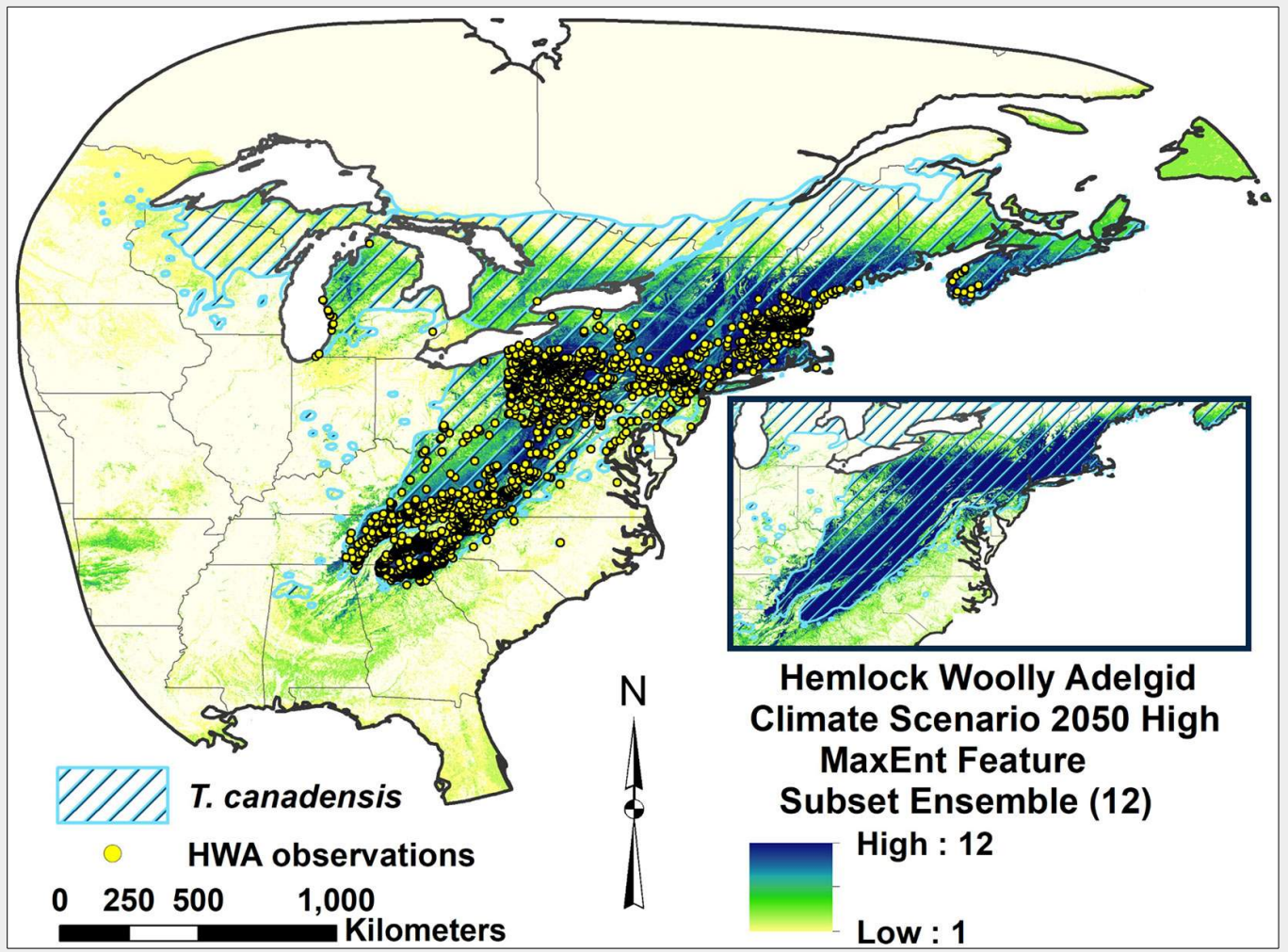

Fig. 2 - Hemlock woolly adelgid introduced range MaxEnt feature subset ensemble model projection over eastern North America for contemporary climate. The scale indicates number of models in agreement on HWA suitability.

mum temperature of the warmest month (bio5) averaging $34.24 \pm 0.63^{\circ} \mathrm{C}$. The corresponding extreme values for these climate features from current HWA occurrence observations in eastern North America were similar at $-15.00{ }^{\circ} \mathrm{C}$ (bio6), $-7.20{ }^{\circ} \mathrm{C}$ (bio11), and $32.00{ }^{\circ} \mathrm{C}$ (bio5).

Reverse-cast native range distribution maps

The RSFSA-selected MaxEnt feature subset ensemble models developed from the
HWA introduced range were reverse-cast to the native ranges in Asia and western North America and overlaid with the HWA occurrence observations and host Tsuga spp. ranges (Fig. 3, Fig. 4). The MaxEnt ensemble model projected high suitability over most of the native HWA range in Japan, Central Taiwan, and Ulleung Island, Republic of Korea (Fig. 3). The introduced range HWA models also projected suitable habitat in the continental range in Asia, but higher suitability was not as well correlated with HWA occurrences. MaxEnt model suitability was generally high for the HWA occurrences in the Cascade Mountains of West North America, with less suitability projected for HWA occurrences eastwards beyond $-121.5^{\circ} \mathrm{W}$ in Washington, Oregon, and Idaho (Fig. 4). Sensitivity of the eastern North America HWA model projection to Asian islands did not significantly differ from sensitivity in eastern North America, but sensitivity was lower for projections to the Asian continent and western North

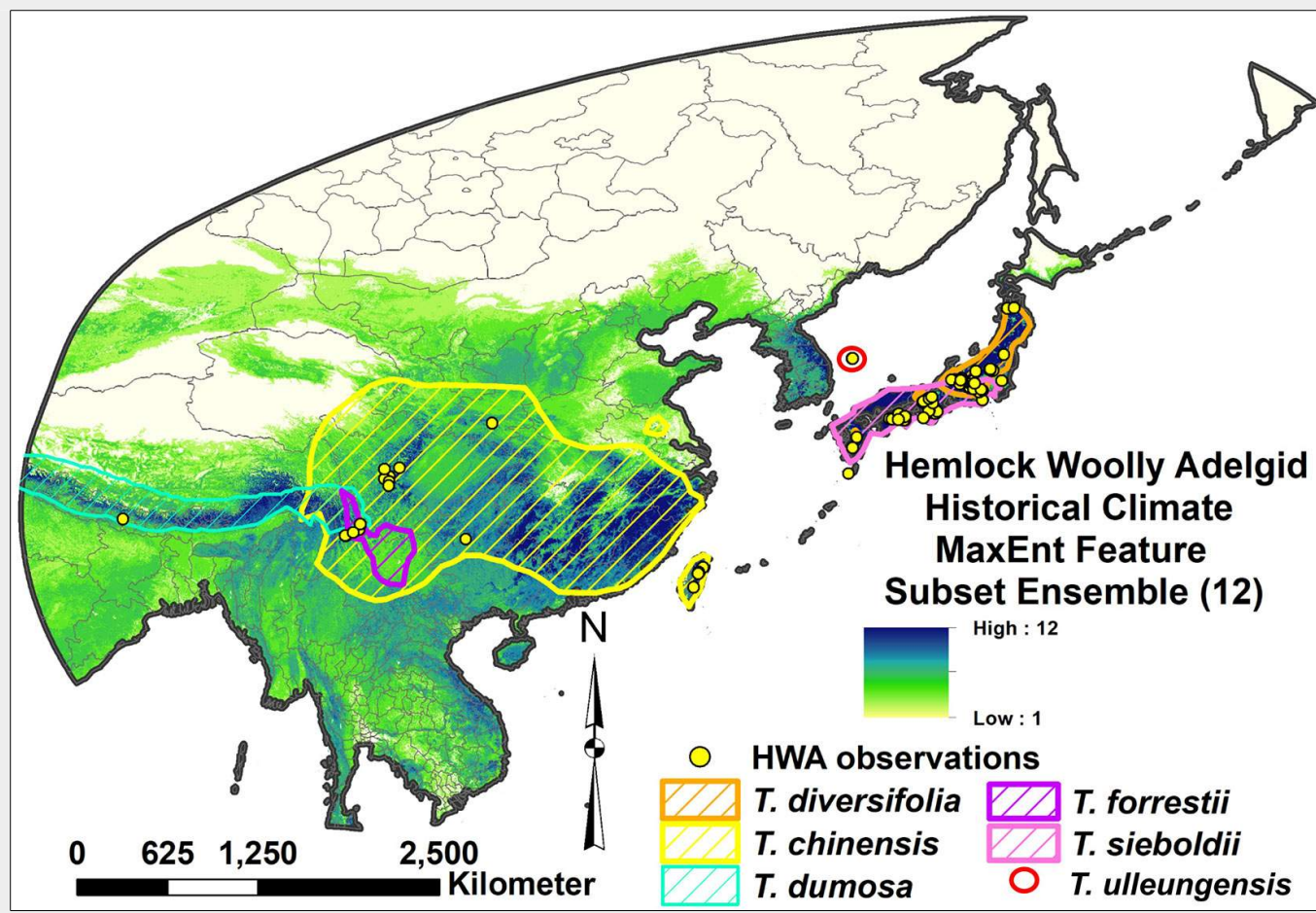

Fig. 3 - Hemlock woolly adelgid introduced range MaxEnt feature subset ensemble model projection over native East Asian range for contemporary climate. The scale indicates number of models in agreement on HWA suitability. 
Fig. 4 - Hemlock woolly adelgid introduced range MaxEnt feature subset ensemble model projection over native western North American range under contemporary climate. The scale indicates number of models in agreement on HWA suitability.

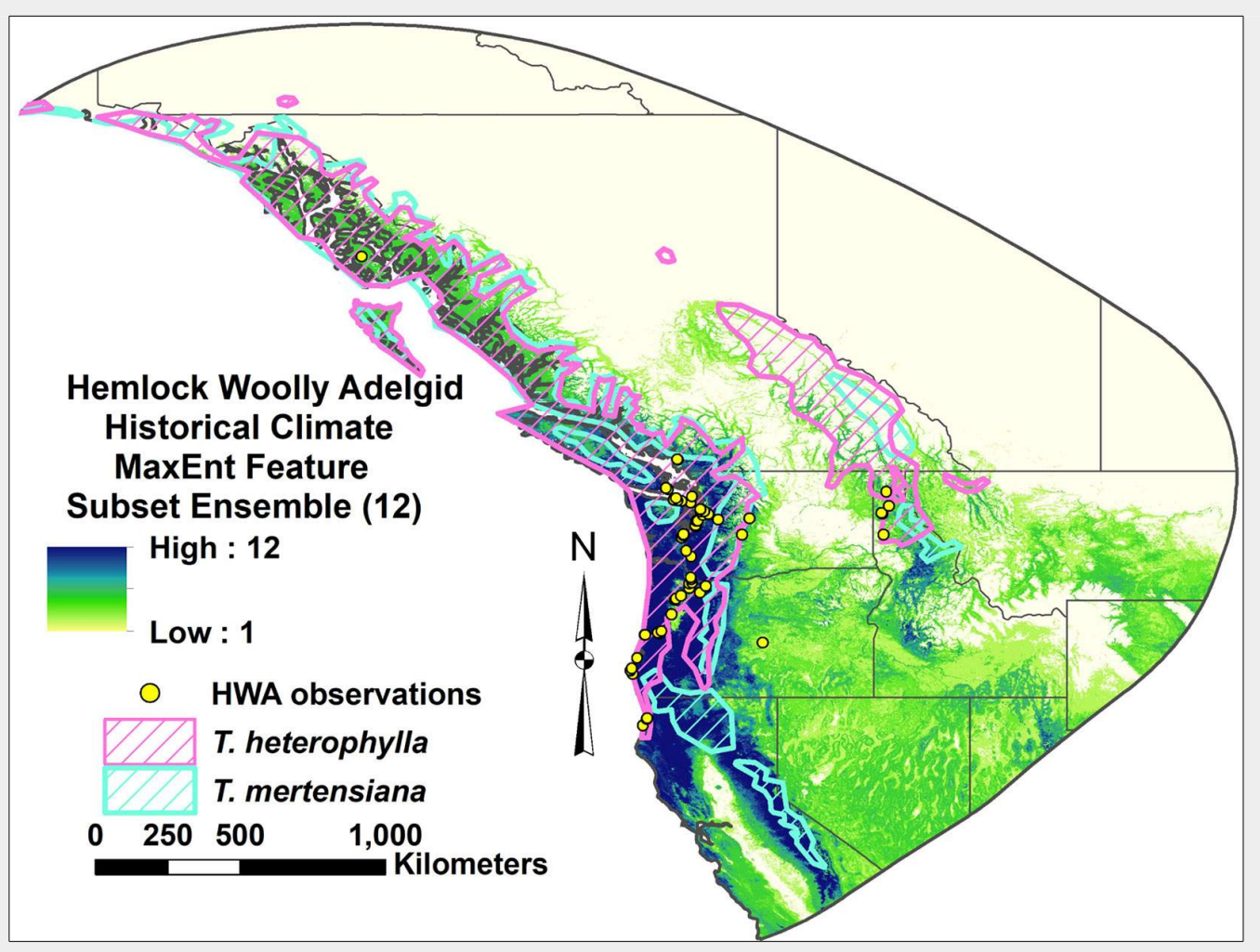

America (Fig. S3A in Supplementary mate- dices for model projections over the three lands, and West North America were highly rial). Sensitivity reverse transferability in- native ranges of Asian continental, Asian is- variable and they did not significantly differ

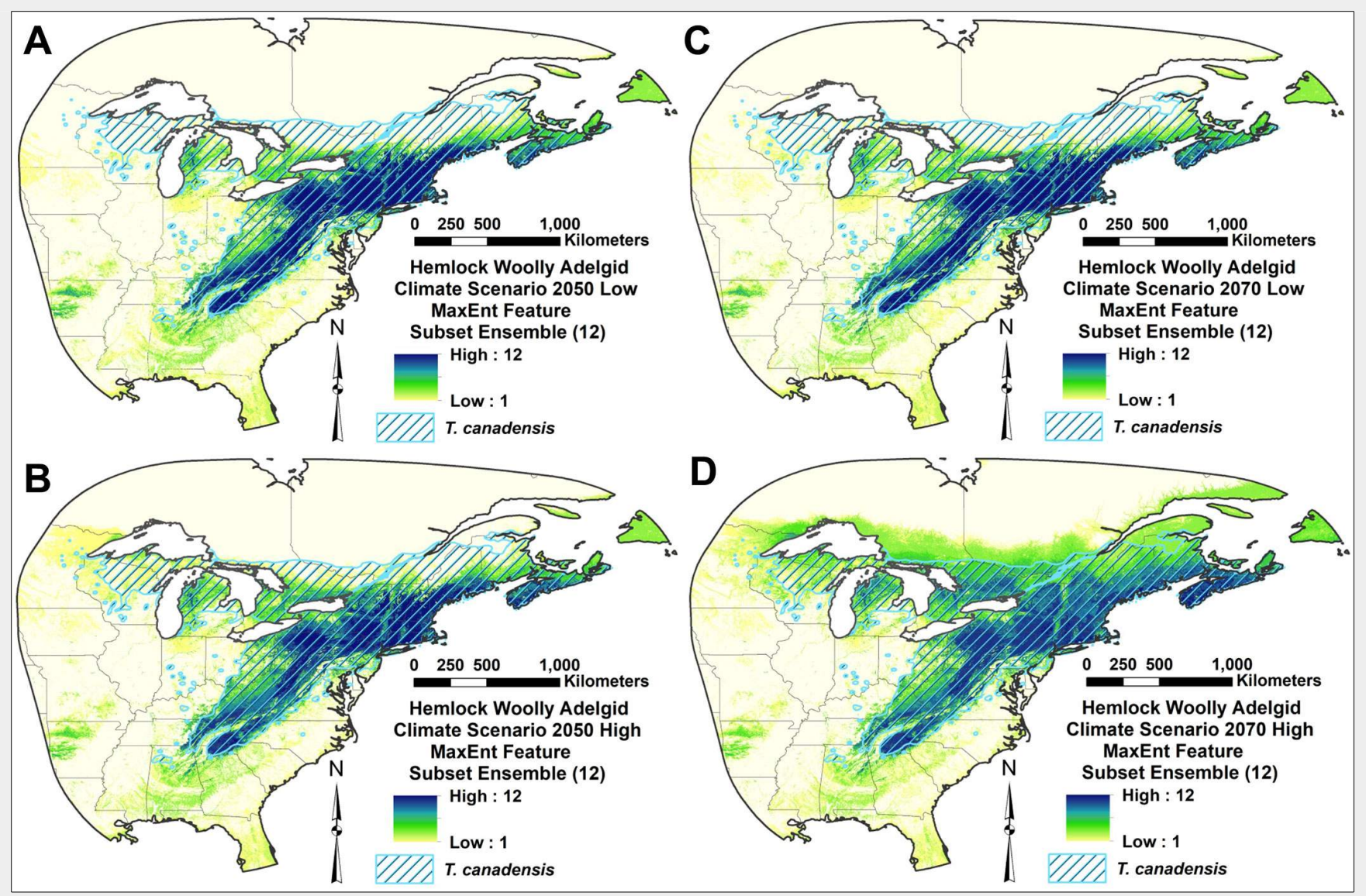

Fig. 5 - Hemlock woolly adelgid introduced range MaxEnt feature subset ensemble model projection over eastern North America for four future climate scenarios: (A) 2050he26; (B) 2050he85; (C) 2070he26; and (D) 2070he85. The scale indicates number of models in agreement on HWA suitability. 


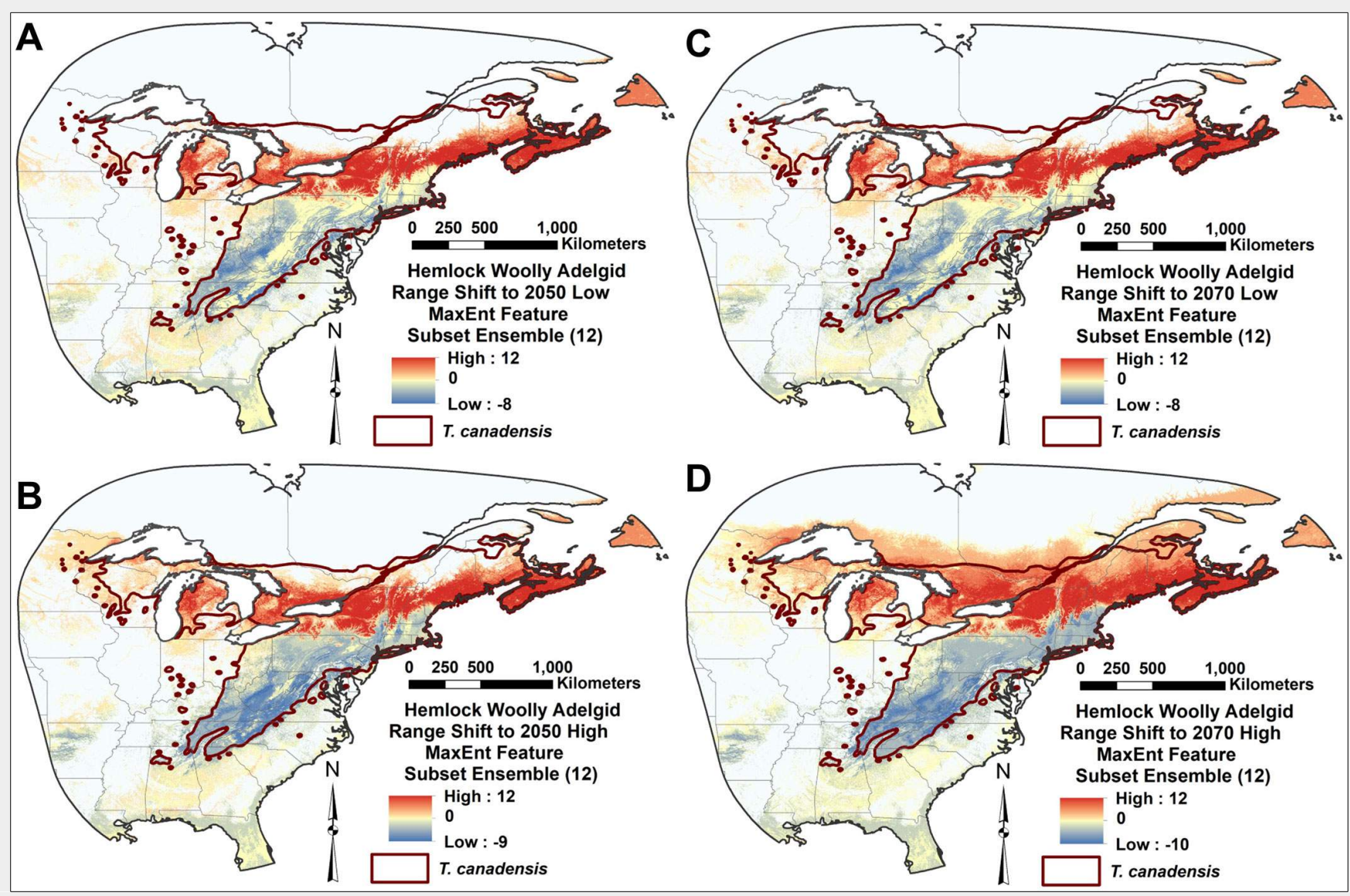

Fig. 6 - Hemlock woolly adelgid future range shift in eastern North America (red: range addition; yellow: no change; blue: range loss) represented by subtracting introduced range MaxEnt feature subset ensemble model for contemporary climate from corresponding ensemble models of four future climate scenarios: (A) 2050he26; (B) 2050he85; (C) 2070he26; and (D) 2070he85. The scale indicates change in the number of models in agreement on HWA suitability.

(Fig. S3B). There was a borderline non-significant linear trend for lower sensitivity for MaxEnt models $(\mathrm{P}=0.061)$ in the Asian island range with higher numbers of climatic variables included in the models (Fig. S3D in Supplementary material).

\section{Introduced range future climate distribution maps}

All four of the future climate RSFSA-selected MaxEnt HWA ensemble models projected expanded suitability to the north and east in North America (Fig. 5A-D, Fig. 6A-D). Both the northward and eastward shifts of the centroids of the 12 MaxEnt models were significantly different from zero for all future climate scenarios $(P<$ 0.02; Welch t-test with Holm correction) (Fig. S4A-B). The northward shift for the high $\mathrm{CO}_{2}$ emission scenario of 2070 (2070he85) was significantly greater than shifts of the corresponding 12 models for other climate scenarios $(\mathrm{P}<0.05$; paired Welch t-test with Holm correction - Fig. S4A in Supplementary material). Under the 2070he85 climate scenario, most of the northern portion of the current native range of the eastern hemlock is projected as highly suitable for HWA. The mean estimated HWA range shifts towards the north varied between $222.12 \pm 92.45 \mathrm{~km}$ (2050he26) and $467.64 \pm 198.85 \mathrm{~km}$ (2070heo85
- Fig. S4A). Mean eastward expansions in suitability ranged from $110.32 \pm 66.24$ to $164.03 \pm 152.99 \mathrm{~km}$, respectively (Fig. S4B). The projected suitable area for HWA did not significantly differ among historical and future climate scenarios, being especially highly variable for future scenarios (Fig. S4C). The number of climatic variables included in the MaxEnt models, ranging from one to three of six variables, produced no significant linear trend in the amount of centroid shift northwards or eastwards ( $P$ $>0.3$; F-test of linear regression - Fig. S5). The mean elevation of MaxEnt model areas did not significantly differ among the future climate scenarios in either the northern or the southern portions of the HWA eastern North American range $(P<0.05$, paired Welch t-test with Holm correction Fig. S6 in Supplementary material).

\section{Discussion}

\section{Feature selection}

Soil features, followed by climatic and topographic features, were the most influential variables in our introduced eastern North American range of HWA feature-selected niche models. Important soil features for HWA, such as proportion of silt from $0-5 \mathrm{~cm}$ and Ochrepts, probably reflect important variables for the primary HWA host of $T$. canadensis in eastern North America. Earlier studies developing random forest niche models for $T$. canadensis identified climate, land cover (e.g., \% agriculture), and soil property features as important (Iverson et al. 2008, Prasad et al. 2014). Important potential soil features for T. canadensis in these studies included soil productivity (not utilized in this study) and soil texture (\% coarse soil), which relates to the silt proportion found as important in this study. Prasad et al. (2014) reported the Inceptisols soil order as important in models for T. canadensis, which corresponds with our finding of the Ochrepts and Udepts suborders of Inceptisols as among the three most important soil suborders in the HWA models (Tab. S2 in Supplementary material). The most important climate variables previously identified for $T$. canadensis models were July mean temperature followed by annual precipitation (Prasad et al. 2014), which relates to the mean January and February precipitation variables found important for HWA in this study.

Although minimum winter temperatures have been previously identified as an important limiting factor for HWA distribution in eastern North America (Paradis et al. 2008, McAvoy et al. 2017, Tobin et al. 2017), only the mean October minimum temperature was utilized among the 27 climate fea- 
tures selected in our 12 six-variable HWA niche models, and it was of minor importance (Tabs. S1-S2). In contrast, the feature selection method in our study identified mean November PET and mean maximum temperature for February as the most important climate variables for accurately modeling HWA distributions (Tab. S2). Although many niche modeling studies include only the 19 Bioclim variables for climate indices, the monthly AET/PET and temperature/precipitation indices were much more important in our study.

Slope was the most important topographic feature identified for HWA models in this study, being ranked as the second most important feature overall. Higher slopes probably represent an important feature of $T$. canadensis habitats. Finer scale (30 $\mathrm{m}$ resolution) topographic features, such as elevation and distance to stream, have been found to affect the landscape-level spatial pattern and performance of both HWA and hemlock hosts (Kantola et al. 2014). However, Trotter \& Shields (2009) found that elevation explained only $2 \%$ of the variation in HWA survival in the eastern USA.

\section{Introduced range distribution maps}

The 12 feature-selected HWA MaxEnt models for eastern North America covered areas with minimum values for minimum temperature of the coldest month and mean temperature of the coldest quarter of $-15.80^{\circ} \mathrm{C}$ and $-7.97^{\circ} \mathrm{C}$, respectively. These temperature indices correspond well to the corresponding minimum values for HWA occurrence observations of $-15.00{ }^{\circ} \mathrm{C}$ and $-7.20{ }^{\circ} \mathrm{C}$, respectively. Skinner et al. (2003) found that only $14 \%$ of the most northern HWA in eastern North America survived from exposure to $-15{ }^{\circ} \mathrm{C}$ in March. Tobin et al. (2017) also reported high HWA mortality after exposure below $-15{ }^{\circ} \mathrm{C}$. The $-15{ }^{\circ} \mathrm{C}$ limit is also close to the value of -15.8 ${ }^{\circ} \mathrm{C}$ representing the minimum values for the average minimum temperature of the coldest month found over the areas of MaxEnt HWA models for eastern North America. Consequently, the current North American range may be close to the northern limit for HWA under contemporary climates, although, over the course of time, HWA may develop greater cold tolerance permitting northern expansion in the future (Skinner et al. 2003). Our historical climate data represents the years 1950-2000, and the mean annual temperature has already elevated since 2000 (Dukes et al. 2009). Consequently, the potential suitable range of HWA may have already slightly shifted towards north. According to Parmesan (2006), numerous species have already responded to the recent reasonably mild climate change.

The current projected HWA range from our MaxEnt models covers much of the eastern hemlock distribution in the US and minor areas in southern Canada, including southern Nova Scotia. The projected range extends farther north along the Atlantic coast than it does inland. Most of the midcontinental region of the eastern hemlock range may be unsuitable, except southwestern Michigan, mainly along the coast of Lake Michigan. More maritime climate corresponds better to the native range of the species and thus may be more suitable. Under the historical climate, the northernmost part of the range of eastern hemlock above $45^{\circ} \mathrm{N}$ may be unsuitable for the species.

The maximum value for the maximum temperature of the warmest month within the projected HWA distribution was slightly higher than the maximum temperature found for HWA occurrence observations $\left(34.24{ }^{\circ} \mathrm{C}\right.$ versus $32.00{ }^{\circ} \mathrm{C}$ ). The projected range of HWA extends slightly south of the range of eastern hemlock, and the host species distribution is already restricting the southern boundary of HWA occurrence. The effect of heat exposure on HWA populations is less studied. Mech (2015) observed a cumulative effect of temperature on HWA mortality, reaching up to $100 \%$ at temperatures above $+30^{\circ} \mathrm{C}$, supporting our projections for the southern range of HWA distribution.

\section{Reverse-casting to other regions}

Similar climate between native and novel environments is considered as basic requirement of successful invasion (Thuiller et al. 2005). Optimally, models of the potential range of HWA would also be developed from Asian occurrence observations. However, large portions of the native range of HWA from China and westwards had inadequate HWA occurrence data. Menke et al. (2009) modeled an invasive ant species distribution using data from the invaded range, and found that disparities in sampling and regional variations in the climatic conditions can induce prediction errors outside the occupied invaded area.

Although there is incomplete information on the full range of HWA range in Asia, our reverse cast projection to the native region was in general accordance with the HWA distribution in Asia, especially for island regions (Fig. 3). All 12 of the selected HWA Maxent models developed from eastern North America occurrences projected suitability in the Japanese islands, where the genotype originates. No hemlock or HWA observations have been published from the most northern Hokkaido Island, and most of this island was projected as unsuitable according to all 12 models. The MaxEnt ensemble model also projected high suitability for other known HWA populations, such as those in Taiwan and Ulleung Island of Republic of Korea (Havill et al. 2016). This successful projection of the introduced range model to these portions of the native range may also indicate that HWA is at or close to equilibrium in the eastern North America. The lower sensitivity of the eastern HWA model for projec- tions to continental Asia and western North America support the Asia islands origination of the eastern North American population.

We also derived the temperature extremes for the HWA occurrence observations in Japan, and they were similar to those within the eastern North America. The minimum value for the minimum temperature of the coldest month (bio6) in Japan was $-15.00{ }^{\circ} \mathrm{C}$, and the maximum value for the maximum temperature of the hottest month (bio5) was $32.2{ }^{\circ} \mathrm{C}$. The mean temperature of the coldest quarter in Japan (bio11: $-9.6{ }^{\circ} \mathrm{C}$ ) suggests higher tolerance for cold during the winter season than the results indicated by the MaxEnt models $\left(-7.97 \pm 0.63{ }^{\circ} \mathrm{C}\right)$. This may indicate that HWA can tolerate colder winter temperatures in eastern North America than estimated and could spread further north than our models project under historical climate.

Expansive occurrence data for the current HWA distribution in western North America was not available. However, the area of suitable habitat projected by all 12 eastern North America MaxEnt models generally matches much of the HWA occurrence observations in the region, especially along the Cascade Mountains (Fig. 4). This projected range includes most of the western portions of the native ranges of western hemlock, T. heterophylla (Raf.) Sarg., and mountain hemlock, T. mertensiana (Bong.) Carrière, from northern California to the southernmost part of British Columbia (Fig. 4). However, only a portion of the models project suitability around HWA occurrences in Idaho to the East.

The reverse-cast HWA MaxEnt models project that Japan and the Cascade Mountains region of Washington and Oregon best match environmentally with the invasive HWA range in eastern North America. These areas generally match with the sources of the primary predators introduced and established for HWA control in eastern North America, including Laricobius nigrinus (Coleoptera: Derodontidae) from western North America and Sasajiscymnus tsugae (Coleoptera: Coccinelidae), and L. osakensis from Japan (Havill et al. 2014). MaxEnt model projections could be used for refining collection source locations for approved or potential biocontrol agents. For example, the success of introductions of more cold tolerant strains of $L$. nigrinus from more interior western US locations into New England (Havill et al. 2014, Mausel et al. 2011) might benefit by collecting from the southernmost distributions of Tsuga spp. in Idaho and Montana, where the environment may more closely match that of the eastern HWA populations (Fig. 4).

\section{Future MaxEnt projections}

Future range shifts of forest insect pests due to the climate change in northern parts of North America and Europe are an- 
ticipated (Vanhanen et al. 2007, Haughian et al. 2012). Minimum temperatures increased by $3.3^{\circ} \mathrm{C}$ in southeastern US between 1960 and 2004 (Dukes et al. 2009). During that period, outbreaks of the southern pine beetle (Dendroctonus frontalis Zimmermann) extended towards north by about $200 \mathrm{~km}$. Vanhanen et al. (2007) suggest a range shift of $500-700 \mathrm{~km}$ to north for the nun moth (Lymatria monacha L.) and gypsy moth (Lymantria dispar L.) in similar latitudes in Europe, by the end of this century. The phenology of HWA has already altered in western North Carolina due to milder winters (Leppanen \& Simberloff 2017).

Our models predict a range shift in the potential distribution of HWA; 221-468 km to the north and $110-164 \mathrm{~km}$ to the east. The major consensus of MaxEnt model projections under the high emission scenario for 2070 (2070he85) indicates HWA suitability throughout most of the northern limit of the eastern hemlock to about $46^{\circ} \mathrm{N}$ (Fig. 5, Fig. 6). Some of the model projections extend northwards beyond the current hemlock distribution. Small isolated areas in the North may remain uninfested by HWA according the MaxEnt projections. Paradis et al. (2008) estimated the future HWA suitability in the northeastern US using a threshold of $-5^{\circ} \mathrm{C}$ of mean winter temperature. According to their higher emissions scenario, by the end of this century, all the northeastern states in the USA will be potentially suitable for HWA. Our MaxEnt projection estimates a similar range expansion. Our projected northern HWA range under high emission $2050 \mathrm{he} 85$ scenario roughly corresponds to the border of USA and Canada in the northeast and the latitude of ca. 35 degrees, which include wide areas in the southern Canada (Fig. 5, Fig. 6). Ellison et al. (2018) projected similar northward HWA spread in 2050 climates, but they project further spread above Lake Ontario to $46^{\circ} \mathrm{N}$, which is only projected as suitable in our later 2070 he 85 models. In addition, they projected no 2050 HWA spread into Nova Scotia, where HWA is currently found and which is projected as suitable in both our current and future climate HWA models. Based upon winter temperatures and related HWA mortality, McAvoy et al. (2017) suggested that HWA may almost reach the northern range of the eastern hemlock distribution, which extends to about $46.5^{\circ}-48^{\circ} \mathrm{N}$. Further, they suggested that winter survival of HWA would increase in the northern latitudes amplifying the impacts.

Future projections for HWA winter mortality in eastern North America indicate decreasing mortality to the north, with less mortality around the southern tip of the Southern Appalachians (McAvoy et al. 2017). Our future HWA distribution projections similarly indicate higher suitability to the North, but they project slightly lower suitability at the southern range limits (Fig. 5, Fig. 6). Warming climate increases insect metabolism during the growing season and reduces the risk of winter mortality to insect populations (Bale et al. 2002). Fitness may decline if a species encounters temperatures beyond its thermal optimum level (Lemoine \& Burkepile 2012). Heat exposure may shift the southern range of HWA range to the north and upwards in the Southern Appalachians with climate change (Fig. 6), although our models projected no apparent upward shift in elevation (Fig. S6 in Supplementary material). The Southern Appalachians remain suitable within the southern part of the current hemlock range even in the high emission projection for 2070 (2070he85). There is some evidence that the rapid adaptation of insects to climate change can arise from already existing genotypes that are heat-tolerant (Parmesan 2006). Sussky \& Elkinton (2015) proposed that adelgids may have adapted to higher temperatures in the south similarly to their adaption to colder temperatures in the north.

If ENM predictions are not coupled with population growth and dispersal models, they may reveal little of the extent to which the populations may actually cross new geographical barriers. Static future ENM projections are more suitable for mapping the potential range than estimating probability or timing of establishment (Fitzpatrick et al. 2012). However, if the dispersal potential of HWA is taken into account, this species may be able to occupy the entire area of its projected ecological niche (Trotter \& Shields 2009). In addition, the dispersal ability of species may evolve at the range boundaries as a response to the climate change (Parmesan 2006).

In regards to projecting species range shifts, two main concerns have been raised: (1) species occurrence data do not have a stable relationship with environmental factors across space and time; and (2) future suitable environmental combinations cannot be adequately sampled (Menke et al. 2009, Elith et al. 2010). In addition, adaptation during range expansion can be especially rapid in the case of invasive species (Butin et al. 2005). Climate change influences the host plant species as well. These potential effects are concerning for both eastern and Carolina hemlock due to their slow growth rate, restricted environmental preferences, and weak seed dispersal (Hastings et al. 2017).

\section{Interactions and impacts}

Menke et al. (2009) observed that abiotic climatic variables tend to be more relevant predictors over biotic variables, such as habitat related or anthropogenic variables, at coarser spatial scales. However, other factors, such as dispersal, competition, species interactions, and landscape change with various human impacts also influence distributions. Climate not only directly affects herbivorous insect populations, but may indirectly affect them by altering host plant nutrient balance and levels of sec- ondary metabolites (Bale et al. 2002). Population dynamics of insect herbivores respond to a multitude of complex interactions between the insects and their natural enemies and it can be assumed that these interactions are also sensitive to temperature (Björkman et al. 2011).

Our projected suitable areas for HWA may not fully correspond to the conditions where the species can survive and persist. Parmesan (2006) concluded that the effects of genetic constraints and asymmetric gene flow are more pronounced close to the borders of distributions, which could also lead to lower survival. On the northern edges of our projected distribution, lower survival may give rise to isolated local HWA populations with much lower impacts on hemlock communities and ecosystems.

Introduced invasive species are difficult to eradicate (Rejmanek et al. 2005), and prevention of introduction of these species is the most effective form of forest health protection - Thuiller et al. 2005). Management of HWA to mitigate negative impacts is challenging. Trotter \& Shields (2009) outlined four reasons for the rapid spread rate and high impacts of HWA in eastern North America: (1) the species has bivoltine and parthenogenic life cycle, which allows for more rapid reproduction and reduces the Allee effect since the population is not dependent on sexual reproduction; (2) HWA is lacking native predators and parasites, despite major biocontrol efforts with introduced enemies; (3) HWA has many vectors increasing the dispersal potential; and (4) eastern and Carolina hemlocks have overall very poor resistance against the species, although increased density of HWA in a tree can decrease the suitability of a host hemlock. Although the HWA in eastern North America originates from a single genotype reproducing by parthenogenesis (Havill et al. 2016), the introduced population seems to have a high spreading potential and ability for rapid adaptation (Parmesan 2006). These factors may indicate that the changing climate may not have high negative impacts on HWA. Impacts of HWA on hemlock communities may even be pronounced in the future taking the slow adaptation of the hemlock species into account.

Significant impacts of invasive species are determined by more than only their presence in an area (Bradley et al. 2012). Impacts of non-native species are difficult to predict and the intensity of impacts may vary greatly within the invaded area (Kulhanek et al. 2011). Impacts can be assumed less severe at the edge area of suitability. However, lower suitability of the conditions for the host species may increase the risk of high impacts. ENM techniques can be used for modeling risk of invasion using locations with high abundance of an invasive species (Kulhanek et al. 2011). High abundance correlates more strongly with the high impact risk than simple occurrence data. In the case of HWA, this kind of 
abundance data is not available. Adequate abundance data for ENM modeling is rarely collected, especially for invasive species (Bradley et al. 2012). More research is needed on factors affecting HWA abundance at a local scale, including anthropogenic factors, to estimate the risk of high impacts.

McClure (1997) observed higher densities of HWA in Japan on ornamental hemlocks than in hemlocks growing in forests, which he attributed to forests having less optimal conditions for HWA and higher abundance of natural enemies. Morin et al. (2009) found that the abundance of host trees appears to be a major factor in the rate of spread of HWA. Nutritional value and resistance ability, i.e., quality of the host trees may be another important factor for successful HWA invasions. For example, trees in mountainous areas, where they are stressed by climate, may be more vulnerable (Niemelä et al. 1987). The interactions between HWA and hemlocks as well as effects of host tree quality on risk of invasion and intensity of the impacts should be studied further.

\section{Conclusions}

The hemlock woolly adelgid is a significant mortality agent threatening hemlock species and related ecosystems of eastern North America. Eradication of the species is difficult and forest health planning and prevention from introduction are the most effective methods to mitigate the impacts of HWA. MaxEnt models for the invasive range of HWA in eastern North America are influenced by a combination of edaphic, climatic, and topographic variables. The minimum values of $-15.8{ }^{\circ} \mathrm{C}$ for the mean minimum temperature of the coldest month over the range of MaxEnt model projections closely aligns with the minimum $-15{ }^{\circ} \mathrm{C}$ value for HWA occurrences and the observed field cold tolerance of around $-15^{\circ} \mathrm{C}$. In addition, sensitivity of HWA projections are fairly high in the Asian native range with reverse-casted MaxEnt models for eastern North America, especially for the region of the source population in Japan. Consequently, the HWA distribution may be nearing equilibrium in eastern North America. Significant range shifts of 221-468 $\mathrm{km}$ northwards and 110-164 km eastwards were projected by 2050 to 2070 . By 2070 , most of the northeastern range of the eastern hemlock may be suitable for HWA infestation.

\section{Acknowledgments}

This study was made possible by financial aid from the Finnish Academy project "Centre of Excellence in Laser Scanning Research" (CoE-LaSR, decision number 272195) and the University of Helsinki project "Towards semi-supervised characterization and large-area planning of forest resources using airborne laser scanning data acquired for digital elevation modeling". We want to thank Christen Carrington,
Joseph Culin, Denise Dodd, Mark Faulkenberry, Nathan Havill, Nathan Hoover, Craig Largenaire, Tom Macy, Tom McAvoy, Deborah McCullough, Michael Montgomery, Ron Neville, Abe Nielsen, Scott Salom, Bill Trescott, Richard Turcotte, and Jennifer Weimer for their kind help providing accurate HWA records and enabling this study.

\section{Author Contributions}

Tuula Kantola had a leading role in the study design, data preparation, analysis, and writing of the paper. James Tracy had a co-leading role in data analysis and writing. Antonio Trabucco prepared additional data for analysis. All the authors contributed to the study design, writing, and commenting of the content.

\section{Conflicts of Interest}

The authors declare no conflict of interest.

\section{References}

Bale JS, Masters GJ, Hodkinson ID, Awmack C, Bezemer TM, Brown VK, Butterfield J, Buse A, Coulson JC, Farrar J, Good JE, Harrington R, Hartley S, Jones TH, Lindroth RL, Press MC, Symrnioudis I, Watt AD, Whittaker JB (2002). Herbivory in global climate change research: direct effects of rising temperature on insect herbivores. Global Change Biology 8 (1): 1-16. - doi: 10.1046/j.1365-2486.2002.00451.x

Björkman C, Bylund H, Klapwijk MJ, Kollberg I, Schroeder $M$ (2011). Insect pests in future forests: more severe problems? Forests 2: 474485. - doi: 10.339o/f2020474

Bradley BA, Olsson AD, Wang O, Dickson BG, Pelech L, Sesnie SE, Zachmann $\amalg$ (2012). Species detection vs. habitat suitability: are we biasing habitat suitability models with remotely sensed data? Ecological modeling 244: 57-64. doi: 10.1016/j.ecolmodel.2012.06.019

Burns RM, Honkala BH (1990). Silvics of North America: Volume 1, Conifers. USDA Forest Service, Agriculture Handbook 654, Washington, DC, USA, pp. 604-611. [online] URL: http:// www.cabdirect.org/cabdirect/abstract/1991065 3295

Butin E, Porter AH, Elkinton J (2005). Adaptation during biological invasions and the case of Adelges tsugae. Evolutionary Ecology Research 7: 887-900. [online] URL: http://www.evolu tionary-ecology.com/abstracts/v07/1762.html Dormann CF, Elith J, Bacher S, Buchmann C, Carl G, Carré G, Marquéz JR, Gruber B, Lafourcade B, Leitão PJ, Münkemüller T (2013). Collinearity: a review of methods to deal with it and a simulation study evaluating their performance. Ecography 36: 27-46. - doi: 10.1111/j.1600-0587.2012. 07348.x

Dukes JS, Pontius J, Orwig D, Garnas JR, Rodgers VL, Brazee N, Cooke B, Theoharides KA, Stange EE, Harrington R, Ehrefield J, Gurewitch J, Lerdau M, Stinson K, Wick R, Ayres M (2009). Responses of insect pests, pathogens, and invasive plant species to climate change in the forests of northeastern North America: what can we predict? Canadian Journal of Forest Research 39: 231-248. - doi: 10.1139/X08-171

Ehrlén J, Morris WF (2015). Predicting changes in the distribution and abundance of species under environmental change. Ecology Letters 18 (3): 303-314. - doi: 10.1111/ele.12410

Elith J, Kearney M, Phillips S (2010). The art of modelling range-shifting species. Methods Ecology and Evolution 1: 330-342. - doi: 10.1111/j.204 1-210X.2010.00036.X

Ellison A, Orwig D, Fitzpatrick M, Preisser $E$ (2018). The past, present, and future of the hemlock woolly adelgid (Adelges tsugae) and its ecological interactions with eastern hemlock (Tsuga canadensis) forests. Insects 9 (4): 172. doi: $10.3390 /$ insects9040172

Farjon A (1990). Pinaceae: drawings and descriptions of the genera Abies, Cedrus, Pseudolarix, Keteleeria, Nothotsuga, Tsuga, Cathaya, Pseudotsuga, Larix and Picea. Koeltz Scientific Books, Königstein, Germany, pp. 330. [online] URL: http://www.cabdirect.org/cabdirect/abstr act $/ 19920656698$

Fitzpatrick MC, Preisser EL, Porter A, Elkinton J, Ellison AM (2012). Modeling range dynamics in heterogeneous landscapes: invasion of the hemlock woolly adelgid in eastern North America. Ecological applications 22: 472-486. - doi: 10.1890/11-0009.1

Freeman EA, Moisen G (2008). PresenceAbsence: an $\mathrm{R}$ package for presence absence analysis. Journal of Statistical Software 23 (11): 1-31. doi: 10.18637 /jss.v023.i11

Fitzpatrick MC, Weltzin JF, Sanders NJ, Dunn RR (2007). The biogeography of prediction error: why does the introduced range of the fire ant over-predict its native range? Global Ecology and Biogeography 16 (1): 24-33. - doi: 10.1111/j.14 66-8238.2006.00258.x

Ford CR, Elliott KJ, Clinton BD, Kloeppel BD, Vose $J M$ (2012). Forest dynamics following eastern hemlock mortality in the Southern Appalachians. Oikos 121 (4): 523-536. - doi: 10.1111/j.16000706.2011.19622.x

Hastings JM, Potter KM, Koch FH, Megalos M, Jetton RM (2017). Prioritizing conservation seed banking locations for imperiled hemlock species using multi-attribute frontier mapping. New forests 48 (2): 301-316. - doi: 10.1007/s110 56-017-9575-7

Haughian SR, Burton PJ, Taylor SW, Curry C (2012). Expected effects of climate change on forest disturbance regimes in British Columbia. Journal of Ecosystems and Management 13 (1): 1-24. [online] URL: http://jem-online.org/index. php/jem/article/view/152

Havill NP, Montgomery ME, Yu GY, Shiyake S, Caccone A (2006). Mitochondrial DNA from hemlock woolly adelgid (hemiptera: Adelgidae) suggests cryptic speciation and pinpoints the source of the introduction to eastern North America. Annals of the Entomological Society of America 99: 195-203. - doi: 10.1603/00138746(2006)099[0195:MDFHWA]2.0.CO;2

Havill NP, Vieira LC, Salom SM (2014). Biology and control of hemlock woolly adelgid. FHTET2014-05, USDA Forest Service, Forest Health Technology Enterprise Team, Morgantown, WV, USA, pp. 21.

Havill NP, Shiyake S, Lamb Galloway A, Foottit RG, Yu G, Paradis A, Elkinton J, Montgomery ME, Sano M, Caccone A (2016). Ancient and modern colonization of North America by hemlock woolly adelgid, Adelges tsugae (Hemiptera: 
Adelgidae), an invasive insect from East Asia. Molecular Ecology 25: 2065-2080. - doi: 10.1111/ mec.13589

Heikkinen RK, Marmion M, Luoto M (2012). Does the interpolation accuracy of species distribution models come at the expense of transferability? Ecography 35: 276-288. - doi: 10.1111/j.160 0-0587.2011.06999.x

Hijmans RJ, Phillips S, Leathwick J, Elith J (2011). Package "dismo": species distribution modeling. Web site. [online] URL: http://cran.r-proj ect.org/web/packages/dismo/index.html

Iverson LR, Prasad AM, Matthews SN, Peters M (2008). Estimating potential habitat for 134 eastern US tree species under six climate scenarios. Forest Ecology and Management 254 (3): 390-406. - doi: 10.1016/j.foreco.2007.07.023 Iverson LR, Prasad AM, Matthews SN, Peters MP (2011). Lessons learned while integrating habitat, dispersal, disturbance, and life-history traits into species habitat models under climate change. Ecosystems 14 (6): 1005-1020. - doi: 10.1007/s10021-011-9456-4

Jiménez-Valverde A, Decae AE, Arnedo MA (2011). Environmental suitability of new reported localities of the funnelweb spider Macrothele calpeiana: an assessment using potential distribution modelling with presenceonly techniques. Journal of Biogeography 38 : 1213-1223. - doi: 10.1111/j.1365-2699.2010.02465.x Kantola T, Lyytikäinen-Saarenmaa P, Coulson RN, Strauch S, Tchakerian MD, Holopainen M, Saarenmaa H, Streett DA (2014). Spatial distribution of hemlock woolly adelgid induced hemlock mortality in the Southern Appalachians. Open Journal of Forestry 4: 492-506. - doi: 10.4236/ojf.2014.45053

Kulhanek SA, Leung B, Ricciardi A (2011). Using ecological niche models to predict the abundance and impact of invasive species: Application to the common carp. Ecological applications 21: 203-213. - doi: 10.1890/09-1639.1

Lemoine NP, Burkepile DE (2012). Temperatureinduced mismatches between consumption and metabolism reduce consumer fitness. Ecology 93: 2483-2489. - doi: 10.1890/12-0375.1

Leppanen C, Simberloff D (2017). Implications of early production in an invasive forest pest. Agricultural and Forest Entomology 19 (2): 217224. - doi: 10.1111/afe.12198

Liang L, Clark JT, Kong N, Rieske LK, Fei SL (2014). Spatial analysis facilitates invasive species risk assessment. Forest Ecology and Management 315: 22-29. - doi: 10.1016/j.foreco.2013. 12.019

Liu C, White M, Newell G (2013). Selecting thresholds for the prediction of species occurrence with presence-only data. Journal of Biogeography 40: 778-789. - doi: 10.1111/jbi.12058

Mausel DL, Van Driesche RG, Elkinton JS (2011). Comparative cold tolerance and climate matching of coastal and inland Laricobius nigrinus (Coleoptera: Derodontidae), a biological control agent of hemlock woolly adelgid. Biological Control 58: 96-102. - doi: 10.1016/j.biocontrol.20 11.04.004

McAvoy TJ, Régnière J, St-Amant R, Schneeberger NF, Salom SM (2017). Mortality and recovery of hemlock woolly adelgid (Adelges tsugae) in response to winter temperatures and predictions for the future. Forests 8 (12):
497. - doi: 10.3390/f8120497

McClure M (1997). Biological control in native and introduced habitats: Lessons learned from the sap-feeding guilds on hemlock and pine. In: "Ecological interactions and biological control" (Ragsdale AD, Nyvall R eds). Westview Press, Boulder, CO, USA, pp. 31-52.

McClure MS, Cheah CAJ (1999). Reshaping the ecology of invading populations of hemlock woolly adelgid, Adelges tsugae (Homoptera: Adelgidae), in eastern North America. Biological Invasions 1 (2-3): 247-254. - doi: 10.1023/A:101 0051516406

McClure MS, Salom SM, Shields KS (2001). Hemlock wooly adelgid. USDA Forest Service, Forest Health Technology Enterprise Team, Morgantown, WV, USA, pp. 19.

Mech AM (2015). Abiotic and biotic factors influencing eastern hemlock (Tsuga canadensis) health and hemlock woolly adelgid (Adelges tsugae) success in the Southern Appalachian Mountains. Doctoral dissertation, The University of Georgia Athens, GA, USA, pp. 114. [online] URL: http://athenaeum.libs.uga.edu/hand le/10724/33289

Menke SB, Holway DA, Fisher RN, Jetz W (2009). Characterizing and predicting species distributions across environments and scales: Argentine ant occurrences in the eye of the beholder. Global Ecology and Biogeography 18: 50-63. doi: 10.1111/j.1466-8238.2008.00420.x

Morin RS, Liebhold AM, Gottschalk KW (2009). Anisotropic spread of hemlock woolly adelgid in the Eastern United States. Biological Invasions 11: 2341-2350. - doi: 10.1007/s10530-0089420-1

Niemelä P, Rousi M, Saarenmaa H (1987). Topographical delimitation of Neodiprion sertifer (Hym, Diprionidae) outbreaks on Scots pine in relation to needle quality. Journal of Applied Entomology 103: 84-91. - doi: 10.1111/j.1439-0418. 1987.tboog62.x

Paradis A, Elkinton J, Hayhoe K, Buonaccorsi J (2008). Role of winter temperature and climate change on the survival and future range expansion of the hemlock woolly adelgid (Adelges tsugae) in eastern North America. Mitigation and Adaptation Strategies for Global Change 13: 541-554. - doi: 10.1007/s11027-007-9127-0

Parmesan C (2006). Ecological and evolutionary responses to recent climate change. Annual Review of Ecology and Systematics 37: 637-669. doi: 10.1146/annurev.ecolsys.37.091305.110100 Peterson AT, Soberón J, Pearson R, Anderson R, Martínez-Meyer E, Nakamura M, Araújo M (2011). Ecological niches and geographic distributions. Princeton University Press, Princeton, NJ, USA, pp. 328. [online] URL: http://books. google.com/books?id=wyFnfox9VioC

Prasad AM, Iverson LR, Peters MP, Matthews SN (2014). Climate change tree atlas. USDA Forest Service, Northern Research Station, Delaware, $\mathrm{OH}, \mathrm{USA}$, Web site. [online] URL: http://www. nrs.fs.fed.us/atlas

R Core Team (2017). R: a language and environment for statistical computing. R Foundation for Statistical Computing, Vienna, Austria. [online] URL: http://www.r-project.org/

Rejmanek M, Richardson DM, Higgins SI, Pitcairn MJ, Grotkopp E (2005). Ecology of invasive plants: state of the art. In: "Invasive Alien Spe- cies: A New Synthesis" (Mooney HA, Mack RN, McNeely JA, Neville LE, Schei PJ, Waage JK eds). Island Press, Washington, DC, USA, pp. 104-1061. [online] URL: http://books.google. com/books?id=KBqYU2dC-b4C

Rohr JR, Mahan CG, Kim KC (2009). Response of arthropod biodiversity to foundation species declines: the case of the eastern hemlock. Forest Ecology and Management 258: 1503-1510. doi: 10.1016/j.foreco.2009.07.002

Skinner M, Parker BL, Gouli S, Ashikaga T (2003). Regional responses of hemlock woolly adelgid (Homoptera: Adelgidae) to low temperatures. Environmental Entomology 32: 523-528. - doi: 10.1603/0046-225X-32.3.523

Soberón J, Peterson AT (2011). Ecological niche shifts, and environmental space anisotropy: a cautionary note. Revista Mexicana de Biodiversidad 82: 1348-1355. [online] URL: http:// kuscholarworks.ku.edu/handle/1808/13672 Spaulding HL, Rieske LK (2010). The aftermath of an invasion: structure and composition of Central Appalachian hemlock forests following establishment of Hemlock woolly adelgid, Adelges tsugae. Biological Invasions 12: 3135-3143. doi: 10.1007/s10530-010-9704-0

Sussky EM, Elkinton JS (2015). Survival and near extinction of hemlock woolly adelgid (Hemiptera: Adelgidae) during summer aestivation in a hemlock plantation. Environmental Entomology 44: 153-159. - doi: 10.1093/ee/nvuo07

Thuiller W, Richardson DM, Pysek P, Midgley GF, Hughes GO, Rouget M (2005). Niche-based modelling as a tool for predicting the risk of alien plant invasions at a global scale. Global Change Biology 11: 2234-2250. - doi: 10.1111/j.13 65-2486.2005.001018.x

Tobin PC, Turcotte RM, Blackburn LM, Juracko JA, Simpson BT (2017). The big chill: quantifying the effect of the 2014 North American cold wave on hemlock woolly adelgid populations in the central Appalachian Mountains. Population Ecology 59 (3): 251-258. - doi: 10.1007/s10144017-0589-y

Tracy JL, Trabucco A, Lawing AM, Giermakowski JT, Tchakerian M, Drus GM, Coulson RN (2018). Random subset feature selection for ecological niche models of wildfire activity in Western North America. Ecological Modelling 383: 5268. - doi: 10.1016/j.ecolmodel.2018.05.019 Trotter RT, Shields KS (2009). Variation in winter survival of the invasive hemlock woolly adelgid (Hemiptera: Adelgidae) across the eastern United States. Environmental Entomology 38: 577-587. - doi: 10.1603/022.038.0309

Urban MC, Phillips BL, Skelly DK, Shine R (2007). The cane toad's (Chaunus [Bufo] marinus) increasing ability to invade Australia is revealed by a dynamically updated range model. Proceedings of the Royal Society of London 274: 1413-1419. - doi: 10.1098/rspb.2007.0114 Vanhanen $\mathrm{H}$, Veteli TO, Päivinen S, Kellomäki S, Niemelä P (2007). Climate change and range shifts in two insect defoliators: gypsy moth and nun moth - a model study. Silva Fennica 41: 621638. - doi: 10.14214/sf.469

Warren DL, Seifert SN (2011). Ecological niche modeling in Maxent: the importance of model complexity and the performance of model selection criteria. Ecological Applications 21: 335342. - doi: 10.1890/10-1171.1 


\section{Supplementary Material}

Appendix 1 - GIS data sources.

Tab. S1 - One hundred nineteen environmental predictor indices ( $1 \mathrm{~km}$ resolution) used in developing 12 selected MaxEnt hemlock woolly adelgid niche models with six of 119 variables.

Tab. S2 - MaxEnt model variable permutation importance for 42 of 119 variables used in top 12 six-variable hemlock woolly adelgid models selected by random subset feature selection algorithm.

Tab. S3 - Hemlock woolly adelgid featureselected MaxEnt model environmental variables.

Fig. S1 - Hemlock woolly adelgid MaxEnt model evaluation statistics.
Fig. S2 - Hemlock woolly adelgid single-variable MaxEnt model variable response curves (logistic output probability of presence vs. variable) for the six top ranked variables from feature-selected models.

Fig. S3 - (A) Sensitivity of introduced hemlock woolly adelgid mean Maxent model projections for introduced (East North America) range and native ranges of Asia continental, Asia island, and West North America; (B) Sensitivity reverse transferability index from introduced range to native ranges; (C) relationship between sensitivity of introduced model for Asia island region and sensitivity of introduced model in introduced region (East North America); (D) relationship between sensitivity of introduced model for Asia island region and percent of climate variables used in model.
Fig. S4 - Characteristics of introduced hemlock woolly adelgid mean Maxent model projections under historical and future climate scenarios in eastern North America.

Fig. S5 - Relationship between northward (A) and eastward (B) shifts of centroids of introduced hemlock woolly adelgid MaxEnt model projections from historical to future $2070 \mathrm{HE} 85$ climates and the ratio of climate variables to the number of total variable per model.

Fig. S6 - (A) North and South regions (divided at $39.721^{\circ} \mathrm{N}$ ) for introduced hemlock woolly adelgid MaxEnt model projections with elevation for MaxEnt historical climate model 1 in two regions.

Link: Kantola_2883@supplo01.pdf 